\title{
The new research of China's inflation
}

\section{Li Hai quan}

Jilin institute of chemical industry,jilin city,jilin province,china

95253766@qq.com

\begin{abstract}
The amount of money should be created, which matches the goods with the domestic money supply over the country that year's goods too much, will inevitably lead to inflation. With M2, therefore, the country's broad money supply and its GDP was created, in comparison with the commodity value of M2 / GDP > 1, their currencies should think is super.
\end{abstract}

Keywords: Inflation; Money supply; The central bank

\section{对我国通货膨胀的新研究}

李海全

吉林化工学院金融工程系, 吉林省, 吉林市, 中国

\section{6@qq.com}

中文摘要. 货币的数量应该与当年本国所创 造的商品相适应，货币供给量超过了本国当 年所创造的商品过多, 必然会引发通货膨胀。 因此，用M2本国的广义货币供给和GDP本国当 年所创造的商品价值相比较, 即 $M 2 / \mathrm{GDP}>1$ 时, 就应当认为本国货币是超发的。

\section{关键词: 通货膨胀; 货币供给; 央行}

\section{一. 我国真实的通货膨胀率}

通货膨胀定义：在信用货币制度下，流 通中的货币数量超过经济实际需要而引起的 货币贬值和物价水平全面而持续的上涨。就 是过多的货币表示有限的商品进而造成商品 价格上涨。

(1). CPI和PPI不能代替通货膨胀率要确 定人民币是否超发, 我们必须知道国内的真 实通货膨胀率，遗憾的是国家统计局并没有 直接公布历年通货膨胀率, 只公布了消费者 物价指数CPI (Consumer Price Index) 和生产 者物价指数PPI(Producer Price Index), 国内行 业进行分析时通常拿这两项指标默认为通货
膨胀率. 尤其是 CPI在大多数分析中, 直接认 为其就是国内通货膨胀率。

需要指出的是: 无论是CPI和PPI都不能等 同于通货膨胀率。物价总水平上升比率即为通 货膨胀率，其包括消费者物价指数CPI、生活 物价指数CLI、生产者物价指数PPI、批发物价 指数WPI、国民生产总值GNP平减指数 (Gross Domestic Product Deflator) 通货膨胀率的计算 是由一系列指标综合生成的.消费者物价指数 CPI和生产者物价指数PPI仅为其中较为重要 的两项指标, 如果以这两项指标等同于通货膨 胀率, 必然让研究和分析产生较大的基础数据 偏差。

\begin{tabular}{|c|c|c|}
\hline 年度 & 消费者物价指数CPI (以上年 $=100$ ) & 生产者物价指数PPI (以上年=100) \\
\hline 2003 & 1.2 & 2.3 \\
\hline 2004 & 3.9 & 6.1 \\
\hline 2005 & 1.8 & 4.9 \\
\hline 2006 & 1.5 & 3 \\
\hline 2007 & 4.8 & 3.1 \\
\hline 2008 & 5.9 & 6.9 \\
\hline 2009 & -0.7 & -5.4 \\
\hline 2010 & 5.1 & 5.5 \\
\hline 2011 & 5.4 & 6 \\
\hline 2012 & 2.6 & -1.7 \\
\hline 平均 & 3.15 & 3.07 \\
\hline
\end{tabular}

图1-1为国家统计局公布的2003年-2012年CPI和PPI

从以上两项指标来看, 我国目前处于温和 的通货膨胀水平 (3\%-6\%), 这也和国家宏观调 
控目标 $3 \%$ 是基本相符的，但是却与我国居民物 价感受大相径庭。

图1-2 为国家统计局公布的我国CPI构成比重

\begin{tabular}{|c|c|c|}
\hline & CPI分类构成 & 权重 \\
\hline 1 & 食品 & $34 \%$ \\
\hline 2 & 娱乐教育文化用品及服务 & $14 \%$ \\
\hline 3 & 居住 & $13 \%$ \\
\hline 4 & 交通通讯 & $10 \%$ \\
\hline 5 & 医疗保健个人用品 & $10 \%$ \\
\hline 6 & 衣着 & $9 \%$ \\
\hline 7 & 家庭设备及维修服务 & $6 \%$ \\
\hline 8 & 烟酒及用品 & $4 \%$ \\
\hline
\end{tabular}

其中应该特别指出的是第三项 “居住” 没 有将房价变动水平计入到 CPI的统计中, 而只 以住房装修费、租金等形式间接的计入统计。 而国际CPI计算中是应该包含居民住房支出 的，从我国平均房价来看：2012年我国平均 房价5791元/每平米, 城镇居民收入 2246 元/ 月（2012年全国人均总收入 26959 元/12个月） 房价每平米单价远超我国居民月人均收入水 平。而 “居住” 项权重却仅占CPI 13\%. 因此 即使仅从CPI来窥测我国真实通胀率, 也是有 一定程度失真。

\section{(2).我国真实的通货膨胀率}

计算通货膨胀率, 需要非常庞大的详尽 的客观的数据, 仅依靠个人或单一机构很难 准确算出, 为保证数据的真实和准确性, 最 稳妥的方法还是依靠国家统计局公布的数 据。虽然国家统计局没有直接公布真实的通 货膨胀率, 但是我们可以根据其公布的历年 GDP和GDP年增长率推算出来。

图1-3 2003年-2012年GDP和GDP年增长率

\begin{tabular}{|c|c|c|}
\hline 年度 & 国内生产总值（GDP） (单位: 亿元人民币) & GDP年增长率 \\
\hline 2003 & 134976 & $10.0 \%$ \\
\hline 2004 & 159453 & $10.1 \%$ \\
\hline 2005 & 183617 & $10.4 \%$ \\
\hline 2006 & 215904 & $11.1 \%$ \\
\hline 2007 & 266422 & $11.9 \%$ \\
\hline 2008 & 316030 & $9.0 \%$ \\
\hline 2009 & 340319 & $9.2 \%$ \\
\hline 2010 & 399759 & $10.4 \%$ \\
\hline 2011 & 468562 & $9.2 \%$ \\
\hline 2012 & 519322 & $7.8 \%$ \\
\hline
\end{tabular}

正常来说: GDP年增长率=（本年GDP上年GDP）/上年GDP

2012年GDP增长率 $=(2012$ 年GDP-2011 年GDP）/2011年GDP

2012 年 GDP 增长率 $=(519322-468562)$ $/ 468562=10.83 \%$

我们看到，2012年GDP增长率应该是 10. $83 \%$ 而不是国家公布的 $7.8 \%$, 二者竟然相
差 $3.03 \%$, 之所以相差是由于国家统计局剔 除了通货膨胀的影响, 因此国家统计局计算 通货膨胀率真正的公式应该是:

2012年GDP增长率= (2012年GDP-2011 年GDP）/2011年GDP-2012年通货膨胀率, 本期 (名义)GDP 总量 $=$ 上期 GDP 总量 (1+GDP增长率+通胀率)

所以，2012年我国真实的通货膨胀率= （ 2012 年 GDP-2011 年 GDP ) /2011 年 GDP-2012年GDP年增长率

即 2012 年真 实通货膨胀率 $=$ (519322-468562）/468562-7.8\%=3.03\%

而国家统计局公布 2012 年 CPI 仅为 $2.6 \%$ 。因此, 正确公式为:

年通货膨胀率 $=($ 本年GDP-上年GDP $)$ /上年GDP-本年GDP增长率

图1-4根据国家统计局数据推算出我国实际通货膨胀率

\begin{tabular}{|c|c|c|}
\hline 年度 & 消费者物价指数CPI (以上年 $=100$ ) & 依据公式测算的通货膨胀率 \\
\hline 2003 & 1.2 & 3.33 \\
\hline 2004 & 3.9 & 8.03 \\
\hline 2005 & 1.8 & 4.75 \\
\hline 2006 & 1.5 & 6.48 \\
\hline 2007 & 4.8 & 11.49 \\
\hline 2008 & 5.9 & 9.62 \\
\hline 2009 & -0.7 & -1.51 \\
\hline 2010 & 5.1 & 7.07 \\
\hline 2011 & 5.4 & 8.01 \\
\hline 2012 & 2.6 & 3.03 \\
\hline 平均 & 3.15 & 6.03 \\
\hline
\end{tabular}

这里要特别指出的是: 图1-4通货膨胀率是国 家统计局在计算GDP年增长率时计算出来并 使用的, 笔者只是用公式反推出来。因此, 可以认为以上通胀率数据是官方隐含数据, 具有一定客观性。

根据图1-4我们可进一步推算出;2003年 -2012年10年间累计通胀率达到 $78.59 \%$, 如果 以 2012 年人民币 100 元面值为例，仅相当于 2003 年人民币 56 元的购买力。（100元 $/ 1.7859=55.99$ 元）。

通过以上分析, 可以得出如下结论:

(1). 以 CPI和PPI指数来说明通货膨胀率 是不准确的, 尤其国家统计局没有把居民住 房支出计入到CPI的统计中。实际上, CPI和 PPI 与实际通胀水平有较大偏差。

(2). 我国目前不仅进入通货膨胀时代, 并 已达到严重通胀标准线（6\%-9\%），10年平 均通胀率已达到 $6.03 \%$, 累计通胀率达到 $78.59 \%$ ，人民币购买力累计贬值达到 $44 \%$ 。 我国通货膨胀是否源于央行货币超发? 
无论官方公布的历年平均CPI 3\%，还是 根据官方数据推算的历年平均通胀率 $6 \%$, 都 有一个不争的事实: 我国目前已进入通货膨 胀时代, 那么产生通货膨胀原因是什么? 是 否是源于央行货币超发?

1. 国内通货膨胀是由近年来央行货币超 发直接造成的。

（1）.根据国际货币基金组织（IMF） 统计 2012 年全球GDP总量为 717073 万亿美 元, 中国GDP为82270万亿美元, 占世界GDP 总量的 $11.47 \%$ 。（如图表2-1）

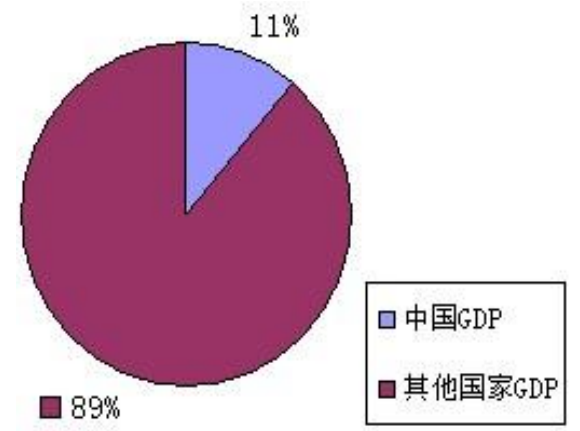

图2-1 2012年中国GDP占世界GDP比重

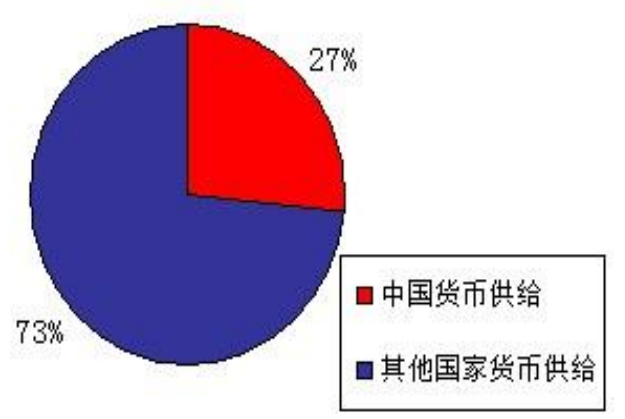

图2-2 2012年中国货币供给占世界货币供给比重

（如图表2-2）2012年世界总货币供应量为 580952 亿美元, 中国货币供给量为 97.42 万亿 人民币（15.46万亿美元）占世界货币供应总 量的 $26.61 \%$ 。

2012全年世界新增货币41667亿美元, 其 中中国新增19458亿美元（12.26万亿元人民 币）, 占世界新增货币总量的 $46.7 \%$ 。（如图 表2-3)

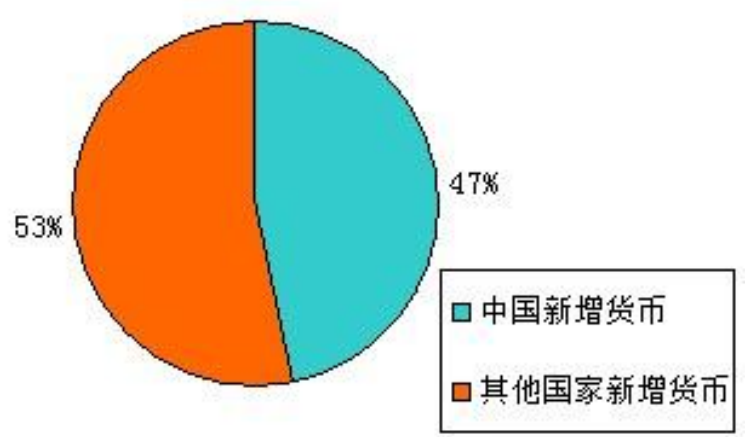

图2-3 2012年我国新增货币占世界新增国币比重

2012 年中国创造了全球 $1 / 9$ 的财富，人 民币存世总量却超过了全球货币总量的 $1 / 4$ 。当年新发行货币更是接近全球新增货 币的 $1 / 2$ 。货币超发是指货币发行增长速度 超过货币需求的增长速度, 即货币发行量超 过了维持经济正常运行所需要的货币量。根 据货币学基本理论, 一个国家或地区经济每 增长出 1 元价值, 作为货币发行机构的中央 银行也应该供给货币 1 元, 超出 1 元的货币供 应则视为超发。货币学派创始人弗里德曼曾 说过: “通货膨胀无论何时何地皆为货币现 象”。

（2）部分学者认为: 既然货币总量应该 与一国所创造的财富相适应。那么就应该拿 广义货币量M2与本年GDP相比较, 货币是否超 发看 $M 2 / G D P$ 是否大于 1 ? 如果大于 1 , 就认为 存在货币超发。这实际上提出了判断货币是 否超发的一个新标准:

图2-4为美国M2/GDP (数据来源: 美国联邦储备局 FED)

\begin{tabular}{|c|c|c|c|c|}
\hline 年度 & 广义货市供给量 (M2) & GDP & M2/GDP & 通胀率 \\
\hline 2003 & 60338 & 109610 & $55.05 \%$ & $2.27 \%$ \\
\hline 2004 & 63990 & 116860 & $54.76 \%$ & $2.68 \%$ \\
\hline 2005 & 66555 & 124220 & $53.57 \%$ & $3.39 \%$ \\
\hline 2006 & 70502 & 133989 & $52.62 \%$ & $3.24 \%$ \\
\hline 2007 & 74569 & 140618 & $53.03 \%$ & $2.85 \%$ \\
\hline 2008 & 82119 & 143690 & $57.15 \%$ & $3.85 \%$ \\
\hline 2009 & 84656 & 141190 & $59.95 \%$ & $-0.34 \%$ \\
\hline 2010 & 87926 & 146578 & $59.99 \%$ & $1.64 \%$ \\
\hline 2011 & 96130 & 149509 & $64.30 \%$ & $1.71 \%$ \\
\hline 2012 & 102500 & 156847 & $65.35 \%$ & $2.80 \%$ \\
\hline 平均 & & & $57.58 \%$ & $2.409 \%$ \\
\hline
\end{tabular}

从该图表可以看出，从2003年-2012年 10年来美国平均通胀率仅为 $2.409 \%$, 而且这 么低的通胀率是在以下几种条件上产生:

1. 是在美元扩张性货币政策背景下通胀率。

从2008年-2012年，美联储连续四次实 施美元量化宽松政策（QE：Quantitative Easing）（量化宽松时间为QE1：2008年11 月25日 QE2：2010年11月4日 QE3：2012年9 月 14 日 QE4:2012年12月 13 日）, 美元扩张性 
货币政策的实施造成5年间造成币值大幅贬 值（人民币兑美元汇率从2008年11月24日的 6. 8304升值到2012年12月 31 日的6. 2855，美 元兑人民币累计贬值达到 $8 \%$ ）。

2. 是将居民购房支出计入CPI并权重高达 42. $69 \%$ 条件下的通胀率。

美国在计算CPI时候与中国最大不同在 于不仅将居民购房支出计入 CPI计算中并且

“居住”一项权重高达 $42.69 \%$ 而中国仅将住 房装修费、租金计入居住支出并且权重仅为 13. $2 \%$, 直接后果就是中国政府对CPI严重低 估。如果中国政府将居民购房支出计入CPI 计算中并将 “居住”一项权重提升到 $40 \%$, 保守估计中国CPI不会低于10\%。

图2-5 两国CPI具体构成与权重:
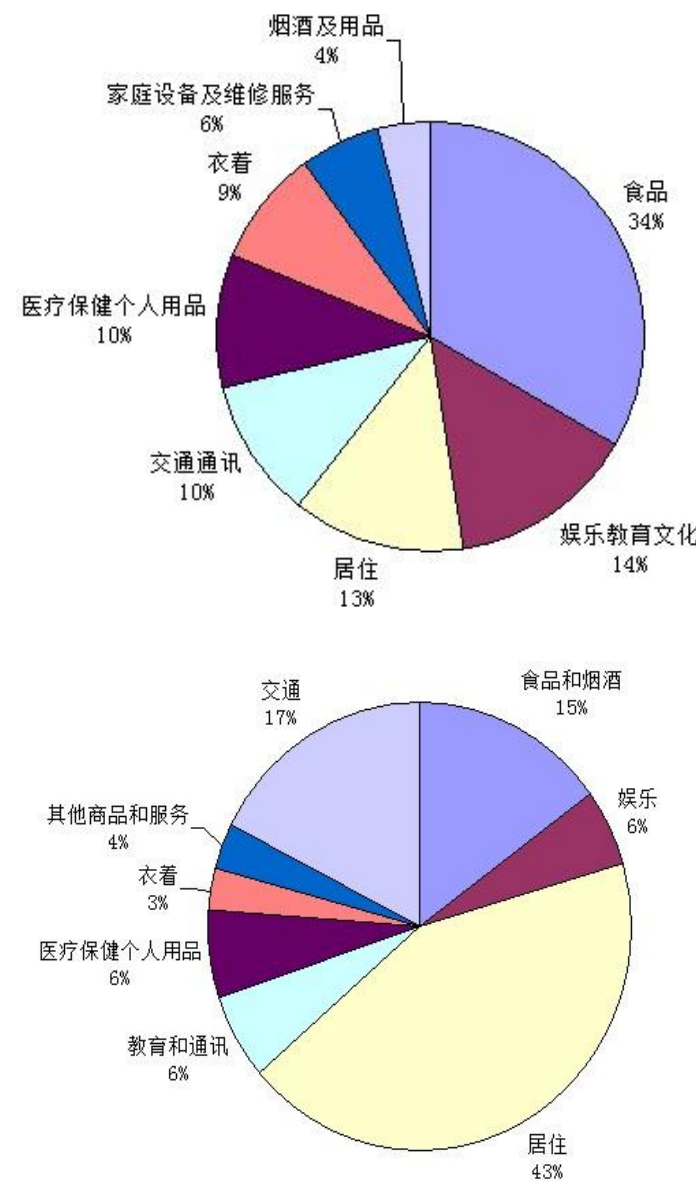

如图2-6为中国 $\mathrm{M} 2 / \mathrm{GDP}$ (数据来源: 中国人民银行)

\begin{tabular}{|c|c|c|c|c|}
\hline 年度 & 广义货币供给量 (M2) & GDP & M2/GDP & 通胀率 \\
\hline 2003 & 221222 & 134976 & $163.9 \%$ & 3.33 \\
\hline 2004 & 253207 & 159453 & $158.8 \%$ & 8.03 \\
\hline 2005 & 298755 & 183617 & $162.7 \%$ & 4.75 \\
\hline 2006 & 345603 & 215904 & $160.7 \%$ & 6.48 \\
\hline 2007 & 403442 & 266422 & $151.4 \%$ & 11.49 \\
\hline 2008 & 475166 & 316030 & $155.3 \%$ & 9.62 \\
\hline 2009 & 606225 & 340319 & $178.1 \%$ & -1.51 \\
\hline 2010 & 725851 & 399759 & $181.6 \%$ & 7.07 \\
\hline 2011 & 851590 & 468562 & $181.8 \%$ & 8.01 \\
\hline 2012 & 974142 & 519322 & $187.6 \%$ & 3.03 \\
\hline 平均 & & & $168.2 \%$ & 6.03 \\
\hline
\end{tabular}

\begin{tabular}{|c|c|c|c|c|c|c|c|}
\hline 年度 & 中国 (M2) & 美国 (M2) & 美元兑人民市汇事 & 中国M2/美国M2 & 中国GDP/美国GDP 中国通胀率/美困通胀率 \\
\hline 2003 & 26728 & 60338 & 8.2767 & $44.30 \%$ & $12.52 \%$ & $146.70 \%$ \\
\hline 2004 & 30593 & 63990 & 8.2765 & $47.81 \%$ & $16.53 \%$ & $299.63 \%$ \\
\hline 2005 & 37019 & 66555 & 8.0702 & $55.62 \%$ & $18.22 \%$ & $140.12 \%$ \\
\hline 2006 & 44258 & 70502 & 7.8087 & $62.78 \%$ & $19.32 \%$ & $200.00 \%$ \\
\hline 2007 & 55231 & 74569 & 7.3046 & $74.07 \%$ & $21.41 \%$ & $403.16 \%$ \\
\hline 2008 & 69524 & 82119 & 6.8346 & $84.66 \%$ & $30.63 \%$ & $249.87 \%$ \\
\hline 2009 & 88782 & 84656 & 6.8282 & $104.87 \%$ & $34.77 \%$ & $98.83 \%$ \\
\hline 2010 & 109600 & 87926 & 6.6227 & $124.65 \%$ & $39.19 \%$ & $431.10 \%$ \\
\hline 2011 & 135153 & 96130 & 6.3009 & $140.59 \%$ & $48.81 \%$ & $468.42 \%$ \\
\hline 2012 & 154982 & 102500 & 6.2855 & $151.20 \%$ & $52.45 \%$ & $108.21 \%$ \\
\hline
\end{tabular}

从两国图表对比来看, 我们能得出以下结论:

1. 自2009年起，人民币货币供给超过美 元供给。到 2012 年，人民币货币供给是美元 供给的 $151.2 \%(154982 / 102500=1.512$ 倍 $)$. 这 对于并不是世界主要结算币种的人民币来 说, 确实有些不可思议。

2. 以2012年为例, 中国用1.5倍的货币， 创造了仅相当于美国 $52.45 \%$ 的GDP，10年间平 均通货膨胀率为美国通胀率的 2.5 倍 (254.6\%)。

3. 货币使用效率中国仅为美国的 $1 / 3$, 即 中国同样创造美国 1 单位商品所需要货币却 是美国的 3 倍, 3 倍与通胀率 2.5 倍之间是否存 在着某种联系?

综合以上分析得出: 由于中国较低的货 币使用效率，货币流动速度仅为美元的 $1 / 3$, 因此只能依靠多发行货币以量的优势弥补质 的不足。即以中国目前的货币使用效率, 如 果想要创造出2012年美国156847亿美元的 GDP, 中国需要3. 09163*102500=316892亿美 元的广义货币供给（M2），以2012年美元兑 人民币汇率来看, 相当于1991825亿元人民币 （2012年中国M2 974142亿元人民币）。

因此，中国政府在较低的货币使用效率 条件下, 为防止出现高速经济发展造成人民 币流动性不足瓶颈出现, 只能依靠货币发行 的量来弥补货币使用效率质的不足。这是造 成货币超发的直接原因, 而超过商品供给的 货币又直接造成国内产生 $6 \%$ 的通货膨胀 (而 这 $6 \%$ 通胀率又是没有将居民购房支出统计出 来的, 如果以美国的住房支出标准来算, 中 国通胀率将会更高）。直接来说，就是以 $6 \%$ 
或以上的通胀率为代价促进年 $7.8 \%$ 以上的 GDP增速。

总结：经济增长会增加对货币的需求, 而我国的货币使用效率较低, 为保证货币充 足流动性以满足国内经济高速发展要求。央 行只有选择货币超发, 以货币的量弥补效率 质的不足。央行行长周小川于2010年11月财 新峰会上指出: “2008年以来, 我们采用扩 张性的货币政策, 即 “出拳要重, 出手要快’, 所有这些举措不可能没有超调”

结论: 正是央行的货币超发, 造成了2003 年-2012年, 中国平均 $6 \%$ 较为严重的通货膨 胀。

\section{References}

[1] Li Dong. Jilin province agricultural product export trade competitiveness of forecast and analysis [Z]. Net of paper of kyushu journal, 2009.

[2] Yuan XiaoXia,Jilin province agricultural exports studies $[\mathrm{J}]$. Chinese science and technology periodical database, 2013.

[3] Lin Lingli. on the impact of foreign direct investment on zhejiang province foreign trade export empirical research. [r]. Journal of zhejiang institute of finance and economics school of finance, 2012nihao

[4] the teacher qiu yun. Optimize the structure of our countryexportcommodities problem discussed in this paper. [J] shanxi finance and tax college journal, 2010 (12) : 46 to 48

[5] Wei Feng Shen Kunmeng. Change the way of our country export commodities structure domain trade development [J]. Journal of international trade issues, 2009 (10) : 9 to 17

[6] Hu Lin: zhao xuegang. Some discussionson the innovation of tourism culture connotation [J], jiangxi social science, 2003 (1).

[7] Li Xuejiang: tourism culture [J], dongyue review, 2004 (11).
[8] Liu jiang: tourism culture - the source of tourism sustainable development [J], special BBS, 2005 (2).

[9] Wang Jiqing: w.k.che Korea tourism development model of government leading [J], BBS in northeast China, 2005 (9).

[10] Jiang Lin, li zhijun fai: Chinese citizens to travel to South Korea tourism market analysis - in six major tourist hotspot cities in our country, for example [J], travel journal, 2005 (2). 